Review

\title{
From Molecular Pathology of COVID-19 to Nigella Sativum as a Treatment Option: Scientific Based Evidence of Its Myth or Reality
}

\author{
Muhammad Atif ${ }^{1}$, Farrah $\mathrm{Naz}^{2}$, Junaid Akhtar, ${ }^{3,4}$, Muhammad Imran ${ }^{3}$, Sidrah Saleem ${ }^{3}$, \\ Javed Akram ${ }^{5}$, Muhammad Imran ${ }^{6}$, and Muhammad Ikram Ullah ${ }^{1}$
}

\begin{abstract}
COVID-19 virus is a causative agent of viral pandemic in human beings which specifically targets respiratory system of humans and causes viral pneumonia. This unusual viral pneumonia is rapidly spreading to all parts of the world, currently affecting about 105 million people with 2.3 million deaths. Current review described history, genomic characteristics, replication, and pathogenesis of COVID-19 with special emphasis on Nigella sativum (N. sativum) as a treatment option. N. sativum seeds are historically and religiously used over the centuries, both for prevention and treatment of different diseases. This review summarizes the potential role of $N$. sativum seeds against COVID-19 infection at levels of in silico, cell lines and animal models.
\end{abstract}

KEYWORDS coronavirus, nCoV-19, COVID-19, Nigella sativum, review

Coronaviruses (CoVs) belong to the Nidovirales order of Coronaviridae family which causes numerous illnesses of respiratory tract and respiratory syndromes. ${ }^{(1)}$ CoVs mainly target humans and wild animals such as birds and mammals. ${ }^{(2)}$ Four major subgroups of CoVs have been identified as: $\alpha$-CoVs, $\beta$-CoVs, $\gamma$-CoVs and $\delta$-CoVs with 17 subtypes. ${ }^{(3)}$ A novel coronavirus (2019-nCoV) which is $70 \%$ identical to severe acute respiratory syndrome coronavirus (SARS-CoV) was for the first time reported in December 2019 from Wuhan, China. ${ }^{(4)}$ This unusual viral infection quickly spread to all parts of the world with more than 105 million cases and about 2.3 million deaths globally so far. ${ }^{(5)}$ This virus was first isolated on 7th January, 2020 from a throat swab of COVID-19 patient by Chinese Center for Disease Control and Prevention (CDC). The virus was eventually named as $2019-n C o V$ by World Health Organization (WHO) ${ }^{(6)}$ Initially, a typical COVID-19 patient shows pneumonia-like symptoms, which later on aggravate to many respiratory illnesses like acute respiratory failure and acute respiratory distress syndrome (ARDS). ${ }^{(4,7)}$

\section{Genome (Strains and Evolutionary Capability)}

Viruses belonging to Coronaviridae family are positive sense, single stranded RNA viruses. ${ }^{(8)}$ A coronavirus is a pleomorphic, spherical, and enveloped particle. The virus contains a matrix protein and its RNA is coupled with a nucleoprotein inside a capsid. There are club-shaped projections of glycoproteins on its envelope. The genome of coronavirus encodes 4 structural proteins; envelope (E), membrane (M2), nucleocapsid (N) and spike (S) proteins. ${ }^{(1)}$ The COVID-19 virus attaches to the host surface receptors by its receptorbinding domain (RBD), present on the $S$ protein, which is involved in fusion of the host and viral cell membranes to permit the viral entry into the host cell. ${ }^{(9)}$ The S-protein of coronavirus contains multiple epitopes for its binding to the host cell. Thus the neutralization of S protein, can make it an ideal candidate for vaccine design. ${ }^{(10)}$

Recent phylogenetic analyses of CoVs have shown that COVID-19 is phylogenetically similar to Bat CoV (BCov) and SARS-CoV. ${ }^{(11)}$ SARS-CoV and COVID-19 genomes share an average sequence similarity of $79 \%$ with their S protein is $76.47 \%$ similar. $^{(11)}$

(C)The Chinese Journal of Integrated Traditional and Western Medicine Press and Springer-Verlag GmbH Germany, part of Springer Nature 2021

1. Department of Clinical Laboratory Sciences, College of Applied Medical Sciences, Jouf University, Sakaka (75471), Saudi Arabia; 2. Department of Microbiology, Government College University, Faisalabad (38000), Pakistan; 3. Department of Microbiology, University of Health Sciences, Lahore (54600), Pakistan; 4. Department of Allied Health Sciences, Sargodha Medical College, University of Sargodha, Sargodha (40100), Pakistan; 5. University of Health Sciences, Lahore (54600), Pakistan; 6. University Institute of Diet and Nutritional Sciences, Faculty of Allied Health Sciences, The University of Lahore, Lahore (54590), Pakistan

Correspondence to: Dr. Muhammad Imran, E-mail: mi.bannu@ yahoo.com

DOI: https://doi.org/10.1007/s11655-021-3311-z 
The full-length genome sequencing of COVID-19 virus showed that it is divergent form MERS-CoV and SARS-CoV which caused past epidemics and it belongs to $\beta-\mathrm{CoVs}{ }^{\left({ }^{12)}\right.}$

The phylogenetic analyses of various coronavirus lineages have shown variable number of small open reading frames (ORFs) among different conserved regions of the genome and at the downstream to nucleocapsid gene. The $\mathrm{S}$ gene of coronavirus possesses a unique N-terminal fragment. The genome of all coronaviruses has shown that the important structural genes exist in the direction of $5^{\prime}-3^{\prime}$ at the order of S, E, M, and N. Hemagglutinin-esterase (HE) protein such as $3 \mathrm{a} / \mathrm{b}$ and $4 \mathrm{a} / \mathrm{b}$ proteins are also present in some coronaviruses which play essential role in virus replication and genome repairs. ${ }^{(13)}$

\section{Pathogenesis}

Patients diagnosed with COVID-19 present abnormal respiratory findings, elevated levels of plasma pro-inflammatory cytokines and leukocyte count. ${ }^{(14)}$ COVID-19 targets the respiratory system causing viremia, severe pneumonia, along with the manifestation of ground-glass opacities, and severe cardiac injury. ${ }^{(4)}$ The increased secretions of chemokines and pro-inflammatory cytokines leads to cytokine storm and include fibroblast growth factor 2 (FGF2), granulocyte colony-stimulating factor (GCSF), granulocyte-macrophage colony-stimulating factor (GMCSF), interferon gamma (IFN $\gamma$ ), interferon gammainduced protein 10 (IP10), monocyte chemoattractant protein-1 (MCP1), macrophage inflammatory proteins alpha (MIP1 $\alpha$ ), macrophage inflammatory proteins beta (MIP1 $\beta$ ), platelet derived growth factor subunit B (PDGFB), tumor necrosis factor-alpha (TNF- $\alpha$ ), vascular endothelial growth factor A (VEGFA), interleukin 1 (IL-1) beta (IL1- $\beta$ ), IL receptor antagonist (IL1RA), IL-7, IL-8, and IL-9. ${ }^{(4)}$

COVID-19 virus enters and infects the host cell by the attachment of its $S$ protein with the host cell surface receptor known as angiotensin converting enzyme $2\left(\mathrm{ACE}_{2}\right)$. To completely enter the host cell, the $S$ protein must be primed with a host protease enzyme named as transmembrane protease, serine 2 (TMPRSS2) $^{(15,16)}$ (Figure 1).

After the entrance of COVID-19 virus into the host cell, uncoating of the virus occurs. The transcription and translation of the virus occurs at the host cytoplasmic membranes. This step requires coordination between continuous and discontinuous RNA synthesis which is regulated by a large complex viral replicate protein. This

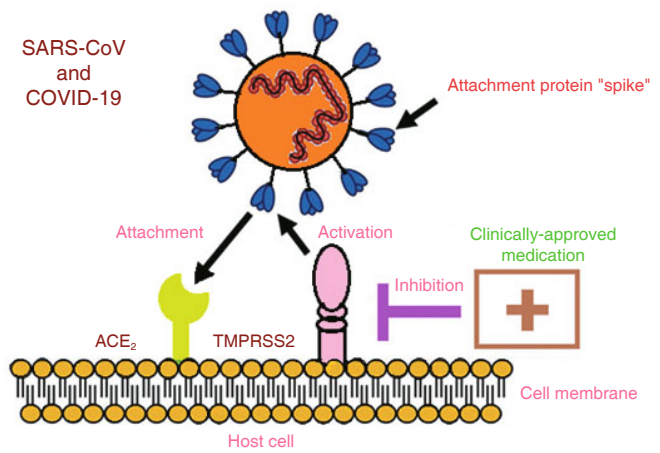

Figure 1. Schematic Representation of Attachment and Entry of SARS-CoV and COVID-19 Virus into Host Cell

Notes: The spike (S) protein of both SARS-CoV and COVID-19 virus uses the same host transmembrane serine protease (TMPRSS2) and angiotensin converting enzyme $2\left(\mathrm{ACE}_{2}\right)$ for its entrance into the host cell. Currently, the commercially available licensed drugs target TMPRSS2 in the lung cells to inhibit COVID-19 infection. ${ }^{(15)}$

complex viral replicate protein is encoded by replicase gene of about $20-\mathrm{kb}$ size and contain 16 viral subunits along with many cellular proteins. ${ }^{(17)}$ Most of the RNA viruses contain RNA helicase, RNA dependent RNA polymerase (RdRp), and protease activities. However, COVID-19 virus replicase has been found to use several RNA processing enzymes that are not present or exceedingly rare in other RNA viruses. These enzymes include putative sequence specific endoribonuclease, ADP ribose 10-phosphatase and 30-50 exoribonuclease, 20-O-ribosemethyltransferase and group 2 coronaviruses cyclic phosphodiesterase. ${ }^{(18)}$ After synthesis, assembly of proteins takes place at the cell membrane and there occurs insertion of the genomic RNA into viral coat to make a mature virion particle which is released by budding from the internal cell membranes. ${ }^{(19)}$

\section{Factors Affecting COVID-19 Viral Pathogenesis}

Cerebrovascular, cardiovascular and diabetes are the most common co-morbidities associated with COVID-19 infection. Many other disorders such as myocardial injury, kidney and hepatic injury, coagulation activation, cellular immunodeficiency, and secondary bacterial infections in COVID-19 patients are also noted. ${ }^{(20)}$ Chronic inflammation and lymphopenia have also been reported in most instances of serious illness. In fact, these findings of COVID-19 patients are closer to the findings observed in patients having SARS and demonstrate a probable common biological process behind these epidemiological disorders. ${ }^{(21)}$

Vaccines and Therapeutic Approaches against COVID-19 Infection

Many types of vaccines and antiviral drugs using $S$ 
protein of coronavirus have been tested. Du, et $\mathrm{al}^{(22)}$ revealed that vaccines can be made using full-length $S$ protein, DNA, viral vector, recombinant $R B D$ protein and recombinant $S$ protein. The only partial success in treatment of COVID-19 infection has been achieved by some recombinant compounds like interferon in combination with ribavirin. ${ }^{(20)}$ It is noteworthy that receptor-binding domain of SARS-CoV has lower affinity for $\mathrm{ACE}_{2}$, while the receptor-binding domain of COVID-19 has a higher affinity for $\mathrm{ACE}_{2}{ }^{\left({ }^{23)}\right.}$ Depending on this information, Gurwitz ${ }^{(24)}$ proposed the use of angiotensin receptor 1 (AT1R) blockers like losartan as a therapeutic approach against COVID-19 infection.

Currently, the treatment of choice against COVID-19 infection is monoclonal antibodies along with a novel adenosine analogue prodrug, remdesivir which was effectively used against Ebola infection in the past. ${ }^{(21,25)}$ Any adaptations in the sequence of the SARS-COV-2 may improve its transmission leading to its high virulence, however, SARS-COV-2 is predicted to become less virulent after human to human transmissions as genetic bottlenecks of RNA viruses usually occur by respiratory droplet transmissions. ${ }^{(26,27)}$

\section{Herbal Treatment against COVID-19 Infection}

The outcomes of COVID-19 infection are mainly dependent on the immune status of the infected subjects, thus any herbal treatment possessing immune-modulatory functions may potentially prevent or cure the disease. ${ }^{(28,29)}$ The recent studies from China have demonstrated that the treatment efficacy of Chinese medicine (CM) was more than $90 \%$, and only few COVID- $19^{(30)}$ subjects were admitted to intensive care unit (ICU). People from China are effectively using a collection of $\mathrm{CM}$ for thousands of years to treat various types of respiratory distress illnesses (RDI). ${ }^{(31,32)}$ Recently it has been shown that Keguan-1-based integrative therapy was safer and more effective than the standard treatment in supressing the development of ARDS in COVID-19 patients. ${ }^{(33)}$

\section{Nigella sativum against COVID-19 Infection}

Recently the synergistic effect of $N$. Sativum (NS) and honey against COVID-19 infection was under clinical trial in Pakistan from April 30 to July 29, 2020. ${ }^{(34)}$ The study recruited 313 patients; 210 were moderate and 103 were severe syndrome patients. In both categories, almost half of the patients were administered honey and Nigella sativa (HNS), while the remaining half were administered placebos. The results showed that the time taken to alleviate COVID-19 symptoms was almost $50 \%$ reduced by HNS treatment.
Moreover, HNS treatment also cleared the virus 4 days earlier than the placebos. The mortality rate in severe cases was 4 times less in HNS-treated group than the placebos. Additionally, there was no side effect of HNS treatment. ${ }^{(34)}$

$N S$ is the member of the Ranunculaceae (buttercup) family which has been widely studied and recognized worldwide. ${ }^{(35)} \mathrm{NS}$ is a native plant in Southern Europe, Northern and Asia Minor. It is extensively cultivated in India and Pakistan. ${ }^{(36-39)}$ Despite its significant cultivation in Eastern Europe and North America, best grown seed are produced in Egypt. ${ }^{(36)}$ It is known as Habbatus Sauda, Allahabhat Alsawada and Alkamoun Alaswad in Islamic society and shuniz, kodera, black cumin or dark caraway in different part of the world. ${ }^{(40)}$

It has been reported by numerous researchers that NS seeds possess many remedial properties such as immunopotentiation, bronchodilatation, antitumor, antihistaminic, antidiabetic and antihypertensive effect. Researches also support its anti-inflammatory properties, antibacterial, hepatoprotective, and gastroprotective properties. These medicinal effects are attributed to its quinone constituents. ${ }^{(41-44)}$

\section{Bioactive Constituents of NS}

So far, several dynamic compounds are recognized from different types of NS seeds, ${ }^{(45)}$ which contain $24.76 \%-40.35 \%$ of fixed oil, $0.5 \%-1.5 \%$ volatile oil, quinones, alkaloids, saponins, and many additional compounds in less amounts. ${ }^{(41)}$ The essential oil has property of yellow to dark amber liquid and possess no fluorescence, even when diluted with alcohol. ${ }^{(46)}$

Fatty acids, more specifically, unsaturated fatty acids are the major component of NS seeds. 50\%-60\% of fatty acids are linoleic acid, $20 \%$ are oleic acid, $10 \%$ are dihomolinoleic acid, while remaining $3 \%$ are eicodadienoic acid. The saturated fatty acids such as palmitic acid and stearic acid are also present but only in lesser amount, $30 \%$ or less. ${ }^{(38)}$ Furthermore, isochinoline alkaloids are present in the form of nigellimin and nigellimin-N-oxide, while pyrazol alkaloids are present in the form of nigellidin and nigellicin. Overall, NS seeds contain $29 \%$ fat followed by protein (27\%), carbohydrates (25\%), crude fiber ( $8 \%)$ and total ash $(5 \%)$. NS seeds also have a little quantity of many vitamins and minerals such as copper, phosphorus, zinc, and iron. ${ }^{(45,46)}$

It is shown by the literature that commercial NS oil is the 
most important ingredient of all NS plants. The oil effect of NS is mainly due to quinone component, especially the essential oil quinone containing thymoquinone (TQ), which is an important bioactive substance that accounts for $30 \%-48 \%$ of all compounds. ${ }^{(47)}$ Other components of NS oil are p-cement, thymohydroquinone (TSQ), dihydroethymoquinone (DHTQ), $\alpha$-thujene, thymol, t-anethole, $\beta$-pinene, $\alpha$-pinene, and $\gamma$-terpinene. ${ }^{(48)} \mathrm{NS}$ seeds are also a good source of $\mathrm{Ca}^{+}, \mathrm{Fe}^{+}$, and $\mathrm{K}^{+}$ions. ${ }^{(49)}$ It is also revealed that $\mathrm{NS}$ seeds contain a novel acetylated triterpene saponin compound (penta hydroxyl pentocyclic triterpene). ${ }^{(50)}$ NS seeds contain flavonoids which have been studied in detail in many studies. ${ }^{(51-53)}$ The other chemical compounds of NS seeds include nigellone, cholesterol, citrostadienol, cycloeucalenol, avenasterol-5-ene, campesterol, gramisterol, lophenol, obtusifoliol, stigmastanol $\beta$-amyrin, butyrospermol, cycloartenol, taraxerol, and tirucallol. ${ }^{(54-58)}$

Importantly, the ratio of thymoquinone in essential oil depends on the geographical origin of the seeds, because Iranian-derived essential oil has lower thymoquinone concentrations than Indian origin essential oil. ${ }^{(46)}$ In one study, concentrations of Iranian-derived NS essential oil contained $13.7 \%$ thymoquinone while Indian-derived essential oil contained up to $50 \%$ thymoquinone. Storing essential oil when exposed to sunlight can cause chemical degradation of thymoquinone and high oligocondensation products. ${ }^{(38)}$ Therefore, due to mild photo-isomerization of thymoquinone, the essential oil needs to be protected from sunlight. Otherwise, it will lead to the accumulation of dithioquinone which is a thymoquinone dimer. ${ }^{(59)}$

\section{In silico Studies of NS Compounds against COVID-19}

A recent study from Bouchentouf and Missoum ${ }^{(60)}$ demonstrated the potential role of NS biochemical components against COVID-19 infection. The technique of molecular docking was used to detect novel possible inhibitors from NS against COVID-19 virus.

\section{Docking Score of NS Compounds and Other Clinical Trial Phase Drugs \\ Currently, different supportive treatment} options for COVID-19 are available. ${ }^{(61)}$ Mostly, these treatment regimens are comprised of chloroquine, hydroxychloroquine, azithromycin, arbidol, remdesivir and favipiravir. ${ }^{(62,63)}$ The best obtained docking score among the drugs under clinical trial was for arbidol, when complexed with 6LU7. ${ }^{(60,64)}$ The docking score of remdesivir followed by chloroquine, hydroxychloroquine and azythromycine. ${ }^{(60,65)}$ The highest energy was provided by favipiravir when complexed with 6LU7. ${ }^{(66)}$ The best obtained docking score among the drugs under clinical test was for remdesivir, when complexed with 2GTB. After attaining the results, it was observed that nigellidine from NS seeds provides the lower energy when complexed with 6LU7, that is preeminent score when matched to other docked complexes. Nigellidine's score is also close to the energy score of chloroquine and better than hydroxychloroquine and favipiravir. When $\alpha$-hederin was complexed with 2GTB active site, the energy score was better than chloroquine, hydroxychloroquine and favipiravir. All other compounds of NS (nigellicine, nigellimine, carvacrol, 6-thymol, thymoquinone, dithymoquinone and thymohydroquinone) included in the study gives energy score related to favipiravir. ${ }^{(60)}$

Favipiravir is an antiviral drug which target RdRP and it is currently approved drug against influenza infection in Japan with half maximal inhibitory concentration $\left(\mathrm{IC}_{50}\right)$ of $0.013-0.48 \mu \mathrm{g} / \mathrm{mL} .^{(66)}$ Chen, et al ${ }^{(66)}$ reported that favipiravir significantly improved the latency to relief for pyrexia and cough. Du, et $\mathrm{al}^{(67)}$ summarized 8 clinical trials and concluded that favipiravir provides a substitute for compassionate use in COVID-19 infection.

\section{Interaction of NS Compounds with 6LU7}

The interactions and 2D diagrams of other NS compounds with 6LU7 and 2GTB were also demonstrated. ${ }^{(68)}$ Maximum 3 hydrogen interactions with amino acids of 6LU7 were observed by NS compounds; $\alpha$-hederin, carvacrol followed by 2 hydrogen interactions of NS compound, nigellicine. Only 1 hydrogen interactions with amino acids of 6LU7 were observed by NS compounds, including thymol, thymoquinone, dithymoquinone and thymohydroquinone, and no interaction in the case of nigellimine. ${ }^{(60)}$

\section{Interaction of NS Compounds with 2GTB}

The interactions between compounds from NS with 2GTB showed that only nigellicine has maximum 3 hydrogen interactions with amino acids of 2GTB. Only one hydrogen interaction was observed in case of nigellidine, nigellimine and thymohydroquinone. The NS compounds with no interactions with 2GTB were carvacrol, thymol, thymoquinone and dithymoquinone. ${ }^{(60)}$

\section{Effects of NS on Coronvirus Cell Lines}

It has been shown that NS extract can reduce the growth of coronavirus in the infected cell line epithelial carcinoembryonic anti-gen-related cell adhesion molecule 1 
(HeLa-CEACAM1a). ${ }^{(69)}$ The NS extract increases IL-8 secretion. IL-8 is possibly involved in priming of dentritic cells (DCs) with $T$ cells during coronavirus infection and stimulation of calcium signaling which may further be associated with the transient receptor potential proteins (TRPs). ${ }^{(70)}$ TRP genes are involved in multiple cellular functions including regulation of intracellular $\mathrm{Ca}^{2+}$ ions. ${ }^{(71)}$ There are 7 sub-families of TRP genes including TRPV (vanilloid), TRPM (melastatin), TRPC (canonical), TRPN and TRPA (ankyrin), TRPML (mucolipin) and TRPP (polycystin). ${ }^{(72)}$ There are several stimuli for triggering TRP channels such as, different growth factors, depletion of intracellular calcium level, different chemicals and temperatures. etc. The triggering pattern and selection of TRPs channels can also be dependent on stimulus. ${ }^{(73)}$

It has been shown that the levels of TRPM6, TRPM7, TRPA1, TRPC4 are downregulated by NS extract. ${ }^{(69)}$ The increased intracellular $\mathrm{Ca}^{2+}$ ions are involved in enhanced viral replication. It is demonstrated that intracellular calcium signaling leads to enhanced production of reactive oxygen species in mitochondria which effect replication of influenza virus. ${ }^{(74)}$ It is also noted that poliovirus infection increases intracellular calcium concentration. ${ }^{(75)}$ Thus, increased intracellular calcium concentration might play crucial role in viral replication. On the contrary, viruses might target those cellular mechanisms which regulate intracellular calcium ion concentration. It was noted that NS extract significantly decreased coronavirus load in HeLa-CEACAM1a cell line. It was observed that after NS extract treatment and $6 \mathrm{~h}$ post infections, the number of viruses was very low and it was $1 / 10$ th as compared to the control amount at $8 \mathrm{~h}$ post infection. ${ }^{(69)}$

\section{NS Mechanism of Action against COVID-19 Infection \\ NS on Mast Cells and Inflammatory Mediators}

One of the most important immune cells that are activated during the pathogenesis of SARS-COV-2 virus are the mast cells (Appendix 1A). The mast cells have important role in inflammation and allergy. Once activated, secretion of histamine and proteases occur. The late mast cell activation leads to the secretion of pro-inflammatory cytokines (IL-1, IL-6, and TNF- $\alpha){ }^{(76)}$ It is observed in COVID-19 subjects that there is systematic elevation of pro-inflammatory cytokines leading to the condition known as "cytokine storm" occurring more specifically in the lungs. ${ }^{(77)}$ The condition may further lead to sepsis with fatal organ damage. ${ }^{(78)}$ Thus the mast cell stabilizers such as ketotifen are most likely to possess antiviral activities. ${ }^{(79)}$ It has been observed in mice model of viral-induced sepsis that all mice treated with ketotifen and antiviral survived as compared to the untreated mice. Moreover, it was observed that virus induced lung lesions were also suppressed by ketotifen. ${ }^{\left({ }^{80}\right)}$ Human studies of rheumatoid arthritis subjects have shown that the serum level of an anti-inflammatory cytokine like IL-10 was significantly increased when oil capsules of NS were administered. ${ }^{(81)}$ Furthermore, it has been observed that two enzymes in human blood cells i.e. 5-lipoxygenase and leukotriene C4 synthase, which can produce inflammatory mediators like leukotrienes and prostaglandins are also suppressed by NS oil and thymoquinone (Appendix 1A). ${ }^{(82,83)}$ The anti-inflammatory and anti-histamine activities of different bioactive components of NS is well established in various animals models. ${ }^{(84,85)}$

\section{NS on Autophagy}

The coronavirus infection leads to activation of unfolded protein response (UPR) as the virus replication require excessive protein biosynthesis to provide the sources for viral proteins and use of endoplasmic membrane for formation of double membrane vesicles (DMVs). ${ }^{(86)}$ The autophagy and UPR are interconnected, activation of UPRs may lead to the induction of autophagy. ${ }^{(87,88)}$ Therefore, it is suggested that COVID-19 infection may promote autophagy via activation of UPR in cells (Appendix 1B).

Presently most of the potential drug candidates (58\%) against COVID-19 infection are autophagy modulators. It is interesting that all these modulators do not seem to directly antagonize the effects of coronavirus infection. The beneficial effects of these drugs are likely due to over accumulation of autophagosomes which leads to apoptotic cell death of virally infected cells and disrupt the viral replication cycle. ${ }^{\left({ }^{89)}\right.}$ It is highly recommended that pharmacological agents which stimulate autophagy may have potentially antiviral effects, more specifically against coronaviruses. ${ }^{(90)}$ A study has shown that one of NS compounds, thymoquinone acts as a cardioprotective agent by promoting autophagy in cardiac patients. ${ }^{(91)}$

\section{NS on Oxidative Stress}

Recently it has been shown that NADPH oxidase-2 (NOX-2) expression is elevated in COVID-19 subjects. ${ }^{(92)}$ Another study has revealed that blockade of NOX-2 in macrophages leads to decreased oxidative stress. ${ }^{(93)}$ It is noted that proinflammatory cytokines and other agonists in endothelial cells may mobilize NOX proteins, leading to local oxidative stress and endothelial dysfunction (Appendix 1C). ${ }^{(94)}$ The endothelial dysfunction in COVID-19 subjects is also 
caused by the production of ROS via $N A D(P) H$ oxidase, leading to reduction in bioavailability of nitric oxide. Decreased level of nitric oxide leads to vasoconstriction, inflammation, and redox imbalance. ${ }^{(95)}$ It is observed that administration of NS thymoquinone improved cisplatin-induced abnormality of enzymatic and nonenzymatic antioxidant defense mechanism in rat intestine. ${ }^{(96)}$ It is also noted in the study of 30 postmenopausal women that consumption of both Allium sativum and NS seeds continuously for 2 months reduces the oxidative stress. ${ }^{(105)}$ Another study revealed that consumption of NS seeds oil with a low-calorie diet significantly reduced oxidative stress in 50 obese subjects. ${ }^{(97)}$

\section{Conclusions}

COVID-19 pandemic has become a serious public health concern with high transmission rate affecting millions of lives worldwide. NS is a potential antiviral therapy for combating COVID-19 infection. Molecular docking studies have indicated that nigellidine and $\alpha$-hederin are major compounds in NS which have capability to constrain COVID-19 infection. NS extract has potential to increase IL-8 levels and alter the expression of TRP genes during coronavirus infection. NS seed extracts also has potential to block cytokine storm and oxidative stress produced during COVID-19 infection. These encouraging and supportive results provided an approach to further perform in vitro and in vivo research.

\section{Conflict of Interest}

No competing financial interests exist.

\section{Author Contributions}

Atif $\mathrm{M}$ and Imran $\mathrm{M}$ designed the study, the first half portion of the manuscript related to COVID-19 was wrote by Naz F and supervised by Atif $M$. The second half portion of the manuscript related to black seeds was wrote by Akhtar $\mathrm{J}$ and supervised by Imran M (from University of Health Science). Saleem $S$ helped in designing the figures. Akram $\mathrm{J}$ provided suggestions for the design of review. Imran $\mathrm{M}$ and Ullah MI revised the manuscript and replied the revisions of the manuscript. All authors read and approved the final manuscript.

Electronic Supplementary Material: Supplementary material (Appendix 1) is available in the online version of this article at http://dx.doi.org/10.1007/s11655-021-3311-z.

\section{REFERENCES}

1. Schoeman D, Fielding BC. Coronavirus envelope protein: current knowledge. Virol J 2019;16:69.

2. Fehr AR, Perlman S. Coronaviruses: an overview of their replication and pathogenesis. Methods Mol Biol 2015;1282:1-23.

3. Dhama K, Pawaiya R, Chakraborty S, et al. Coronavirus infection in Equines: a review. Asian J Animal Veter Adv 2014;9:164-176.

4. Huang CL, Wang YM, Li XW, et al. Clinical features of patients infected with 2019 novel coronavirus in Wuhan, China. Lancet 2020;395:497-506.

5. World Health Organization. Novel coronavirus (2019-nCoV): situation report. 3, 23 January 2020. In: World Health Organization, 2020. Available at: https://www.who.int/docs/default-source/ coronaviruse/situation-reports/20200123-sitrep-3-2019-ncov.pdf [accessed 09 July 2020].

6. World Health Organization. Clinical management of severe acute respiratory infection when novel coronavirus ( $\mathrm{nCoV}$ ) infection is suspected: interim guidance, 25 January 2020. In: World Health Organization, 2020. Available at: https://apps.who.int/iris/ handle/10665/330854 [accessed 09 July 2020].

7. Zhong NS, Yang ZF, Jiang M, et al. A potential Chinese medicine granule suppressing ARDS of COVID-19: Keguan-1. Chin J Integr Med 2020:26:1-2.

8. Lu R, Zhao X, Li J, et al. Genomic characterisation and epidemiology of 2019 novel coronavirus: implications for virus origins and receptor binding. Lancet 2020;395:565-574.

9. Kirchdoerfer RN, Cottrell CA, Wang NS, et al. Pre-fusion structure of a human coronavirus spike protein. Nature 2016;531:118-121.

10. Reguera J, Santiago C, Mudgal G, et al. Structural bases of coronavirus attachment to host aminopeptidase $\mathrm{N}$ and its inhibition by neutralizing antibodies. PLoS Pathog 2012;8:e1002859.

11. Zhou $P$, Yang $X L$, Wang $X G$, et al. Discovery of a novel coronavirus associated with the recent pneumonia outbreak in humans and its potential bat origin. Nature 2020; 579:270-273.

12. Zhu N, Zhang D, Wang $W$, et al. A novel coronavirus from patients with pneumonia in China, 2019. N Engl J Med 2020;382:727-733.

13. Woo PC, Huang Y, Lau SK, et al. Coronavirus genomics and bioinformatics analysis. Viruses 2010;2:1804-1820.

14. Li G, De Clercq E. Therapeutic options for the 2019 novel coronavirus (2019-nCoV). Nat Rev Drug Discov 2020;19:149-150.

15. Hoffmann M, Kleine-Weber H, Schroeder S, et al. SARS-CoV-2 cell entry depends on $\mathrm{ACE}_{2}$ and TMPRSS2 and is blocked by a clinically proven protease inhibitor. Cell 2020;181:271-280.

16. Guo YR, Cao QD, Hong ZS, et al. The origin, transmission and clinical therapies on coronavirus disease 2019 (COVID-19) outbreak-an update on the status. Mil Med Res 2020;7:11.

17. Sola I, Almazan F, Zuniga S, et al. Continuous and discontinuous RNA synthesis in coronaviruses. Annu Rev Virol 2015;2:265-288.

18. Almazan F, Dediego ML, Galan C, et al. Construction of a severe acute respiratory syndrome coronavirus infectious cDNA clone and a replicon to study coronavirus RNA synthesis. J Virol 2006;80:10900-10906.

19. Mclntosh K, Peiris J, eds. Coronaviruses. In: Clinical virology, 3rd edition. American Society of Microbiology; 2009:1155-1171.

20. Chen N, Zhou M, Dong X, et al. Epidemiological and clinical characteristics of 99 cases of 2019 novel coronavirus pneumonia in Wuhan, China: a descriptive study. Lancet 2020;395:507-513.

21. Liu C, Zhou Q, Li Y, et al. Research and development on therapeutic agents and vaccines for COVID-19 and related human coronavirus diseases. ACS Cent Sci 2020;6:315-331.

22. Du L, He Y, Zhou Y, et al. The spike protein of SARS-CoV-a target for vaccine and therapeutic development. Nat Rev Microbiol 
2009;7:226-236.

23. Prabakaran $P$, Xiao $X$, Dimitrov DS. $A$ model of the $A C E_{2}$ structure and function as a SARS-CoV receptor. Biochem Biophys Res Commun 2004;314:235-241.

24. Gurwitz D. Angiotensin receptor blockers as tentative SARS-CoV-2 therapeutics. Drug Dev Res 2020;81:537-540.

25. Sheahan TP, Sims AC, Graham RL, et al. Broad-spectrum antiviral GS-5734 inhibits both epidemic and zoonotic coronaviruses. Sci Transl Med 2017;9:eaal3653.

26. Martinez MA. Compounds with therapeutic potential against novel respiratory 2019 Coronavirus. Antimicrob Agents Chemother 2020;64:5.

27. Cascella M, Rajnik M, Cuomo A, et al. Features, evaluation and treatment coronavirus (COVID-19). In: StatPearls. Treasure Island (FL), 2020. [Updated 2021 July 17]

28. Zhang L, Liu Y. Potential interventions for novel coronavirus in China: a systematic review. J Med Virol 2020;92:479-490.

29. Sharma M, Anderson SA, Schoop R, et al. Induction of multiple pro-inflammatory cytokines by respiratory viruses and reversal by standardized Echinacea, a potent antiviral herbal extract. Antiviral Res 2009;83:165-170.

30. Lee DY, Li QY, Liu J, et al. Traditional Chinese herbal medicine at the forefront battle against COVID-19: clinical experience and scientific basis. Phytomedicine 2020;80:153337.

31. Chen YB, Liu $Q$, Xie $H$, et al. Is Chinese medicine injection applicable for treating acute lung injury and acute respiratory distress syndrome? a systematic review and meta-analysis of randomized controlled trials. Chin J Integr Med 2020;26:857-866.

32. Luo H, Tang Ql, Shang YX, et al. Can Chinese medicine be used for prevention of corona virus disease 2019 (COVID-19)? A review of historical classics, research evidence and current prevention programs. Chin J Integr Med 2020;26:1-8.

33. Wang JB, Wang ZX, Jing J, et al. Exploring an integrative therapy for treating COVID-19: a randomized controlled trial. Chin J Integr Med 2020;26:648-655.

34. Ashraf S, Ashraf S, Ashraf M, et al. Honey and Nigella sativa against COVID-19 in Pakistan (HNS-COVID-PK): a multi-center placebocontrolled randomized clinical trial. MedRxiv 2020.

35. Goreja W. Black seed: nature's miracle remedy. New York: Amazing Herbs Press; 2003:15.

36. Naz H. Nigella sativa: the miraculous herb. Pak J Biochem Mol Biol 2011;44:44-48.

37. Kirtikar K, Basu B. Indian medicinal plants. 2nd edition. Allahabad: Lalit Mohan Publication; 1935:1347-1348.

38. Sharma N, Ahirwar D, Jhade D, et al. Medicinal and phamacological potential of Nigella sativa: a review. Ethnobotanical Leaflets 2009;2009:11.

39. Khan MA. Chemical composition and medicinal properties of Nigella sativa Linn. Inflammopharmacology 1999;7:15-35

40. Salem ML. Immunomodulatory and therapeutic properties of the Nigella sativa L. seed. Int Immunopharmacol 2005;5:1749-1770.

41. Koshak AE, Yousif NM, Fiebich BL, et al. Comparative immunomodulatory activity of Nigella sativa L. preparations on proinflammatory mediators: a focus on asthma. Front Pharmacol 2018;9:1075.

42. Ghosheh OA, Houdi AA, Crooks PA. High performance liquid chromatographic analysis of the pharmacologically active quinones and related compounds in the oil of the black seed (Nigella sativa L.).
J Pharm Biomed Anal 1999;19:757-762.

43. Kanter M. Nigella sativa and derived thymoquinone prevents hippocampal neurodegeneration after chronic toluene exposure in rats. Neurochem Res 2008;33:579-588.

44. Kanter M. Protective effects of Nigella sativa on the neuronal injury in frontal cortex and brain stem after chronic toluene exposure. Neurochem Res 2008;33:2241-2249.

45. Ahmad A, Husain A, Mujeeb $M$, et al. A review on therapeutic potential of Nigella sativa: a miracle herb. Asian Pac J Trop Biomed 2013;3:337-352.

46. Dajani EZ, Shahwan TG, Dajani NE. Overview of the preclinical pharmacological properties of Nigella sativa (black seeds): a complementary drug with historical and clinical significance. $J$ Physiol Pharmacol 2016;67:801-817.

47. Norsharina I, Maznah I, Aied A, et al. Thymoquinone rich fraction from Nigella sativa and thymoquinone are cytotoxic towards colon and leukemic carcinoma cell lines. J Med Plants Res 2011;5:3359-3366.

48. Salehi P, Nasri S, Roghani M, et al. The effect of thymoquinone on shortterm spatial memory, passive avoidance learning and memory of diabetic rats and the involvement of hippocampal oxidative stress. Pajoohandeh J 2012;17:219-227.

49. Al-Naqeep GN, Ismail MM, Al-Zubairi AS, et al. Nutrients composition and minerals content of three different samples of Nigella sativa L. cultivated in Yemen. Asian J Biol Sci 2009;2:43-48.

50. Mehta BK, Mehta P, Gupta M. A new naturally acetylated triterpene saponin from Nigella sativa. Carbohydr Res 2009;344:149-151.

51. AL-Okaily BN. Effect of flavonoids extracted from black cumin (Nigella sativa) and vitamin $\mathrm{E}$ in ameliorating hepatic damage induced by sodium nitrate in adult male rats. Iraqi J Veterinary Med 2012;36:172-181.

52. Elshiekh $\mathrm{Y}$, Abdelmageed M. Phytochemical screening and antimicrobial activity of Striga hermonthica and Nigella sativa seeds. Am J Res Comm 2015;3:24-33.

53. Tubesha Z, Iqbal S, Ismail M. Effects of hydrolytic conditions on recovery of antioxidants from methanolic extracts of Nigella sativa seeds. J Med Plant Res 2011;5:3152-3158.

54. Ali Z, Ferreira D, Carvalho $P$, et al. Nigellidine-4-O-sulfite, the first sulfated indazole-type alkaloid from the seeds of Nigella sativa. J Nat Prod 2008;71:1111-1112.

55. Mehta BK, Pandit V, Gupta M. New principles from seeds of Nigella sativa. Nat Prod Res 2009;23:138-148.

56. Morikawa T, Xu F, Kashima Y, et al. Novel dolabellane-type diterpene alkaloids with lipid metabolism promoting activities from the seeds of Nigella sativa. Org Lett 2004;6:869-872.

57. Morikawa T, Xu F, Ninomiya K, et al. Nigellamines A3, A4, A5, and $\mathrm{C}$, new dolabellane-type diterpene alkaloids, with lipid metabolismpromoting activities from the Egyptian medicinal food black cumin. Chem Pharm Bull (Tokyo) 2004;52:494-497.

58. Nickavar B, Mojab F, Javidnia K, et al. Chemical composition of the fixed and volatile oils of Nigella sativa L. from Iran. Z Naturforsch C J Biosci 2003;58:629-631.

59. Agbaria R, Gabarin A, Dahan A, Ben-Shabat S. Anticancer activity of Nigella sativa (black seed) and its relationship with the thermal processing and quinone composition of the seed. Drug Des Dev Ther 2015;9:3119-3124.

60. Bouchentouf $S$, Missoum N. Identification of compounds from Nigella sativa as new potential inhibitors of 2019 novel coronasvirus (Covid-19): molecular docking study. ChemRxiv Preprint 2020;1-12. 
Available at: https://doi.org/10.26434/chemrxiv.12055716.

61. Gautret $\mathrm{P}$, Lagier JC, Parola $\mathrm{P}$, et al. Hydroxychloroquine and azithromycin as a treatment of COVID-19: results of an open-label non-randomized clinical trial. Int J Antimicrob Agents 2020:105949.

62. Thorlund K, Dron L, Park J, et al. A real-time dashboard of clinical trials for COVID-19. Lancet Digit Health 2020;2:6.

63. Md Insiat Islam R. Current drugs with potential for treatment of COVID-19: a literature review. J Pharm Pharm Sci 2020;23:58-64.

64. Deng L, Li C, Zeng Q, et al. Arbidol combined with $L P V r$ versus LPV/r alone against corona virus disease 2019: a retrospective cohort study. J Infect 2020;81:e1-e2.

65. Grein J, Ohmagari N, Shin D, et al. Compassionate use of remdesivir for patients with severe COVID-19. New Eng J Med 2020;382:2327-2336.

66. Chen C, Huang J, Cheng Z, et al. Favipiravir versus arbidol for COVID-19: a randomized clinical trial. MedRxiv 2020.03.17,20037432.

67. Du YX, Chen XP. Favipiravir: pharmacokinetics and concerns about clinical trials for 2019-nCoV infection. Clin Pharmacol Ther 2020;108:242-247.

68. Adem S, Eyupoglu V, Sarfraz I, et al. Identification of potent COVID-19 main protease (Mpro) inhibitors from natural polyphenols: an in silico strategy unveils a hope against CORONA. 2020. DOI: 10.20944/preprints202003.0333.V1.

69. Ulasli M, Gurses SA, Bayraktar R, et al. The effects of Nigella sativa (Ns), Anthemis hyalina (Ah) and Citrus sinensis (Cs) extracts on the replication of coronavirus and the expression of TRP genes family. Molecular Biol Rep 2014;41:1703-1711.

70. Yoshikawa T, Hill T, Li K, et al. Severe acute respiratory syndrome (SARS) coronavirus-induced lung epithelial cytokines exacerbate SARS pathogenesis by modulating intrinsic functions of monocytederived macrophages and dendritic cells. J Virol 2009;83:3039-3048.

71. Gkika D, Prevarskaya N. Molecular mechanisms of TRP regulation in tumor growth and metastasis. BBA-Molecul Cell Res 2009;1793:953-958.

72. Santoni G, Farfariello V. TRP channels and cancer: new targets for diagnosis and chemotherapy. Endocr Metab Immune Disord Drug Targets 2011;11:54-67.

73. Clapham DE. TRP channels as cellular sensors. Nature 2003;426:517-524.

74. Gong G, Waris G, Tanveer R, et al. Human hepatitis C virus NS5A protein alters intracellular calcium levels, induces oxidative stress, and activates STAT-3 and NF- $\kappa$ B. Proceed Nat Acad Sci 2001;98:9599-9604.

75. Irurzun A, Arroyo J, Alvarez A, et al. Enhanced intracellular calcium concentration during poliovirus infection. J Virol 1995;69:5142-5146.

76. Raymond M, Ching-A-Sue G, et al. Mast cell stabilisers, leukotriene antagonists and antihistamines: a rapid review of effectiveness in COVID-19. Centre for Evidence-Based Medicine 2020. Available at: https://covid19-evidence.paho.org/handle/20.500.12663/1569 [accessed June 27, 2020].

77. Sinha P, Matthay MA, Calfee CS. Is a "cytokine storm" relevant to COVID-19? JAMA Intern Med 2020;180:1152-1154.

78. Graham AC, Temple RM, Obar JJ. Mast cells and influenza A virus: association with allergic responses and beyond. Front Immunol 2015;6:238.

79. Ramos L, Peña G, Cai B, et al. Mast cell stabilization improves survival by preventing apoptosis in sepsis. J Immunol 2010;185:709-716.

80. Hu Y, Jin $Y$, Han $D$, et al. Mast cell-induced lung injury in mice infected with H5N1 influenza virus. J Virol 2012;86:3347-3356.

81. Hadi V, Kheirouri S, Alizadeh M, et al. Effects of Nigella sativa oil extract on inflammatory cytokine response and oxidative stress status in patients with rheumatoid arthritis: a randomized, double-blind, placebo-controlled clinical trial. Avicenna J Phytomed 2016;6:34.

82. Mansour M, Tornhamre S. Inhibition of 5-lipoxygenase and leukotriene C4 synthase in human blood cells by thymoquinone. J Enzyme Inhib Med Chem 2004;19:431-436.

83. Houghton PJ, Zarka R, de las Heras B, et al. Fixed oil of Nigella sativa and derived thymoquinone inhibit eicosanoid generation in leukocytes and membrane lipid peroxidation. Planta Med 1995;61:33-36.

84. Boskabady MH, Keyhanmanesh R, Khamneh S, et al. The effect of Nigella sativa extract on tracheal responsiveness and lung inflammation in ovalbumin-sensitized guinea pigs. Clinics 2011;66:879-887.

85. Keyhanmanesh R, Saadat S, Mohammadi M, et al. The protective effect of $\alpha$-hederin, the active constituent of Nigella sativa, on lung inflammation and blood cytokines in ovalbumin sensitized guinea pigs. Phytotherapy Res 2015;29:1761-1767.

86. Fung TS, Huang M, Liu DX. Coronavirus-induced ER stress response and its involvement in regulation of coronavirus-host interactions. Virus Res 2014;194:110-123.

87. Mehrbod P, Ande SR, Alizadeh J, et al. The roles of apoptosis, autophagy and unfolded protein response in arbovirus, influenza virus, and HIV infections. Virulence 2019;10:376-413.

88. Ghavami S, Yeganeh B, Zeki AA, et al. Autophagy and the unfolded protein response promote profibrotic effects of TGF- $\beta 1$ in human lung fibroblasts. Am J Physiol-Lung Cell Molecul Physiol 2018;314:L493-L504.

89. Shojaei S, Koleini N, Samiei E, et al. Simvastatin increases temozolomide-induced cell death by targeting the fusion of autophagosomes and lysosomes. FEBS J 2020;287:1005-1034.

90. Dong X, Levine B. Autophagy and viruses: adversaries or allies? J Innate Immun 2013;5:480-493.

91. Xiao J, Ke ZP, Shi Y, et al. The cardioprotective effect of thymoquinone on ischemia-reperfusion injury in isolated rat heart via regulation of apoptosis and autophagy. J Cell Biochem 2018;119:7212-7217.

92. Violi F, Oliva A, Cangemi R, et al. Nox2 activation in Covid-19. Redox Biol 2020;36:101655.

93. Wu H, Wang $\mathrm{Y}$, Zhang $\mathrm{Y}$, et al. Breaking the vicious loop between inflammation, oxidative stress and coagulation, a novel anti-thrombus insight of nattokinase by inhibiting LPS-induced inflammation and oxidative stress. Redox Biol 2020;36:101500.

94. Libby $P$, Lüscher T. COVID-19 is, in the end, an endothelial disease. Eur Heart J 2020;41:3038-3044.

95. Rabelo LA, Alenina N, Bader M. ACE $E_{2}$-angiotensin-(1-7)-Mas axis and oxidative stress in cardiovascular disease. Hypertension Res 2011;34:154-160.

96. Shahid F, Farooqui Z, Khan AA, et al. Oral Nigella sativa oil and thymoquinone administration ameliorates the effect of long-term cisplatin treatment on the enzymes of carbohydrate metabolism, brush border membrane, and antioxidant defense in rat intestine. Naunyn-Schmiedeberg's Arch Pharmacol 2018;391:145-157.

97. Namazi N, Mahdavi R, Alizadeh M, et al. Oxidative stress responses to Nigella sativa oil concurrent with a low-calorie diet in obese women: a randomized, double-blind controlled clinical trial. Phytotherapy Res 2015;29:1722-1728.

(Accepted March 10, 2021; First Online September 29, 2021) Edited by TIAN Lin 